\title{
p53- and p73-independent activation of TIGAR expression in vivo
}

\author{
P Lee ${ }^{1}$, AK Hock ${ }^{1}$ KH Vousden ${ }^{* 1}$ and EC Cheung ${ }^{\star, 1}$
}

TIGAR (TP53-induced glycolysis and apoptosis regulator) functions as a fructose-2,6-bisphosphatase and its expression results in a dampening of the glycolytic pathway, while increasing antioxidant capacity by increasing NADPH and GSH levels. In addition to being a p53 target, p53-independent expression of TIGAR is also seen in many human cancer cell lines that lack wild-type p53. Although human TIGAR expression can be induced by p53, TAp63 and TAp73, mouse TIGAR is less responsive to the p53 family members and basal levels of TIGAR expression does not depend on p53 or TAp73 expression in most mouse tissues in vivo. Although mouse TIGAR expression is clearly induced in the intestines of mice following DNA-damaging stress such as ionising radiation, this is also not dependent on p53 or TAp73.

Cell Death and Disease (2015) 6, e1842; doi:10.1038/cddis.2015.205; published online 6 August 2015

TIGAR (TP53-induced glycolysis and apoptosis regulator) is a metabolic enzyme sharing structural similarities to the FBPase2 domain of phosphofructokinase-2/fructose-2,6-bisphosphatase. TIGAR can act to lower the levels of fructose-2,6bisphosphate $\left(\mathrm{F}-2,6-\mathrm{P}_{2}\right)$, an allosteric activator of phosphofructokinase-1 (PFK-1) in the glycolytic pathway. Lowering F-2,6- $\mathrm{P}_{2}$ levels results in decreased PFK-1 activity, thereby decreasing flux through glycolysis and potentially allowing for the diversion of glycolytic metabolites to other pathways such as the pentose phosphate pathway or the hexosamine pathway. ${ }^{1,2}$ Although the detailed effects of TIGAR expression on metabolism remain to be determined, it is clear that TIGAR functions in many cell systems to mediate antioxidant defence through an increase in NADPH and $\mathrm{GSH}^{3-8}$ TIGAR has also been found to act as a 2,3-bisphosphoglycerate phosphatase, which catalyses the conversion of 2,3-bisphosphoglycerate into 3-phosphoglycerate, ${ }^{9}$ although the physiological significance of this activity remains unclear.

TIGAR was identified in human cells as a transcriptional target of the tumour-suppressor protein p53. The human TIGAR possesses two p53-binding sites, human p53-binding site (hBS) 1 and hBS2, where hBS2 is the functional p53binding site. ${ }^{2}$ In the mouse genome, Tigar shows a similar organisation with two potential p53-binding sites, mBS1 and mBS2, in a similar arrangement as human TIGAR. ${ }^{10}$ As a p53 target, TIGAR would be predicted to play a role in tumour suppression and the antioxidant functions of TIGAR would be consistent with a role in protecting from the acquisition of damage. However, TIGAR expression has been found to be elevated in a number of cancer models and tumour types ${ }^{4,11,12}$ through a mechanism that is not dependent on the maintenance of wild-type (WT) p53. Moreover, the expression of TIGAR in human breast cancer was found inversely correlated to the levels of p53. ${ }^{13}$ Taken together, these data suggest that TIGAR can function in a tumour suppressor pathway as part of a p53 response, but may also contribute to cancer development when TIGAR expression is deregulated and uncoupled from p53. In mouse models, loss of TIGAR has been shown to result in a decreased ability to regenerate damaged intestinal epithelium and a restraint on tumour development, both situations where ROS limitation is important. ${ }^{11}$ These results are consistent with the model that the expression of TIGAR may support tumour progression.

Little is known about p53-independent expression of TIGAR, although other transcription factors such as SP1 and $\mathrm{CREB}^{14,15}$ have been implicated. Other members of the p53 family (p63 and p73) are able to activate promoters of p53 targets such as $\mathrm{p} 21^{16,17}$ and these $\mathrm{p} 53$ family proteins can also contribute to the regulation of metabolic gene expression. It is therefore possible that $\mathrm{p} 63$ and $\mathrm{p} 73$ can also regulate TIGAR expression.

To further understand the regulation of TIGAR, we investigate the differences in TIGAR regulation by $p 53$ and its family members. Although both p53 and TAp73 showed activity in promoting the expression of both human and mouse TIGAR reporters in cells, we found that the activation of expression of mouse TIGAR in response to genotoxic stress is not dependent on p53 or TAp73.

\section{Results}

TIGAR expression is varied across tissues. Although we have previously shown TIGAR to be expressed in several mouse tissues, to assess the relative levels of TIGAR expression, protein levels were evaluated across various tissues from WT mice (Figure 1a). TIGAR protein was

\footnotetext{
${ }^{1}$ Cancer Research-UK Beatson Institute, Switchback Road, Glasgow G61 1BD, UK

*Corresponding author: KH Vousden or EC Cheung, CRUK Beatson Institute, Switchback Road, Glasgow G61 1BD, UK. Tel: +44 141 3302424 ; Fax: +44 141 942 0372 ; E-mail: k.vousden@beatson.gla.ac.uk or e.cheung@beatson.gla.ac.uk

Abbreviations: BPAG1, bullous pemphigoid antigen 1; CDDP, cisplatin; DMEM, Dulbecco's modified Eagle's medium; F-2,6- $\mathrm{P}_{2}$, fructose-2,6-bisphosphate; hBS, human p53-binding site; IR, irradiation; iRFP, infrared fluorescent protein; PFK-1, phosphofructokinase-1; PFK-2/FBPase-2, phosphofructokinase-2/fructose-2,6-bisphosphatase; TIFs, tert-immortalised fibroblasts; TIGAR, TP53-induced glycolysis and apoptosis regulator; WT, wild type

Received 25.3.15; revised 17.6.15; accepted 26.6.15; Edited by G Melino
} 
detected in all tissues examined, with highest levels in the muscle and brain. Antibody specificity was confirmed using small intestine tissue from WT and TIGAR-deficient animals after treatment with irradiation (IR), which we have previously shown to increase TIGAR expression. ${ }^{11}$ As expected, TIGAR protein expression increased following IR in the WT animals and was not detected in TIGAR $^{-/-}$animals (Supplementary Figure 1a). Interestingly, TIGAR protein expression in tissues was not completely mirrored by mRNA expression (Figure 1b). For example, the protein expression of TIGAR in the liver and pancreas are similar, however, the levels of TIGAR mRNA in the pancreas are much lower than in the liver. This suggests additional mechanisms to regulate TIGAR protein levels may exist in some tissues.

\section{Mouse TIGAR is not responsive to p53 during genotoxic stress in vitro. Published studies have shown that mouse TIGAR can also be responsive to p53's transcriptional activity $^{10,18,19}$ and p53-deficient mice lose the ability to induce TIGAR expression following myocardial injury. ${ }^{19,20}$ However, TIGAR was also shown to be induced in mouse primary neurons following oxygen and glucose deprivation/ reoxygenation in a p53-independent manner. ${ }^{8}$ To compare the p53-induced expression of TIGAR in mouse and human}

a

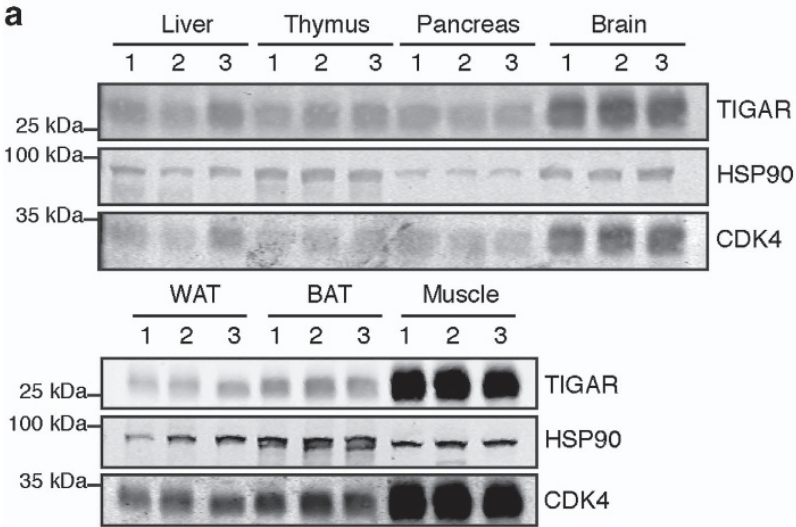

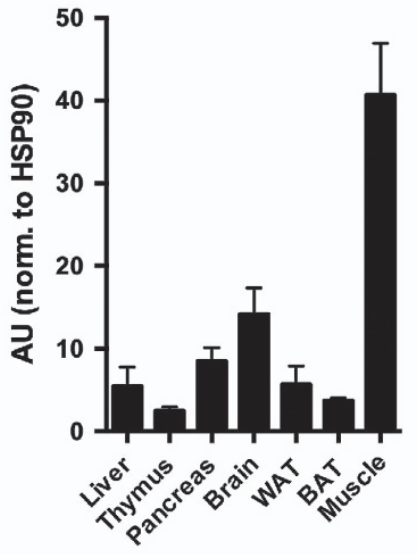

b

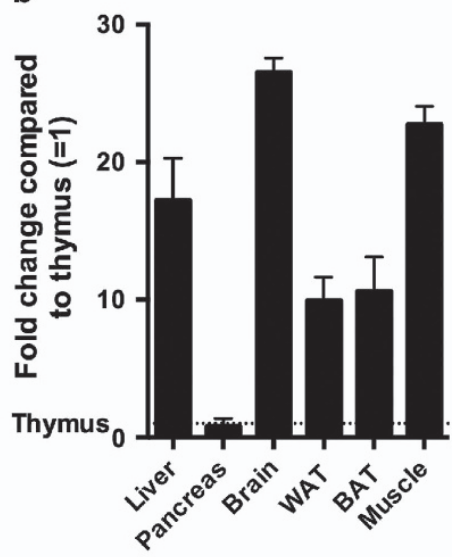

C

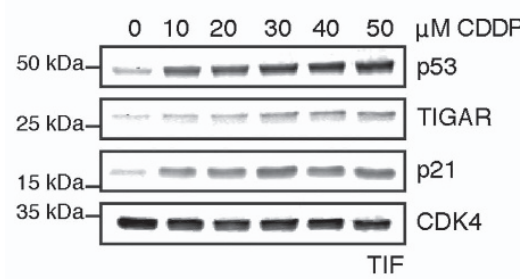

e

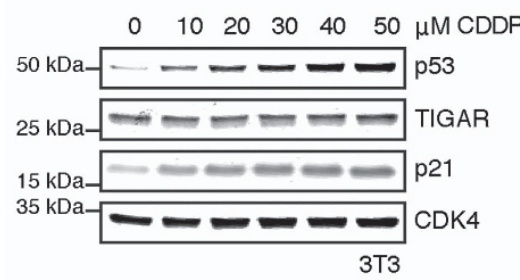

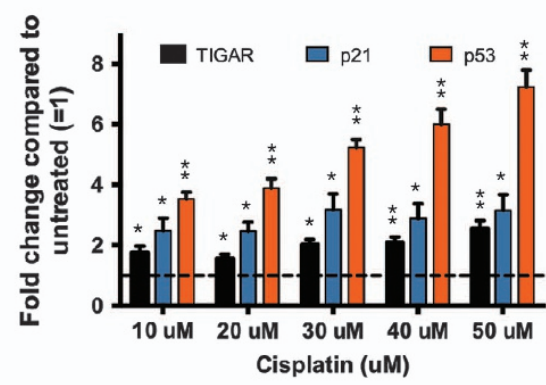

d
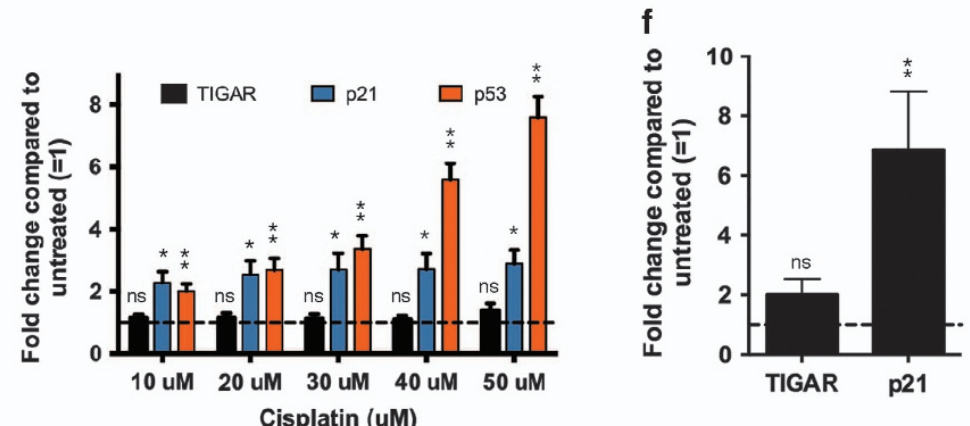

Figure 1 Basal TIGAR expression and its response to p53 activation. (a) Left: Western blot analysis of indicated tissues from three different wild-type (WT) animals. Right: Graph represents quantification of western blots. (b) mRNA expression of TIGAR in indicated tissues of WT animals. (c) Left: Western blot analysis of Tert-Immortalised Fibroblasts (TIFs) treated with indicated concentrations of cisplatin (CDDP) for $24 \mathrm{~h}$. Right: Graph represents quantification of western blots with fold change compared with untreated. (d) mRNA expression of TIGAR and p21 following $24 \mathrm{~h}$ of CDDP treatment $(50 \mu \mathrm{M})$ in TIFs. (e) Left: Western blot analysis of 3T3s treated with indicated concentrations of CDDP for $24 \mathrm{~h}$. Right: Graph represents quantification of western blots with fold change compared with untreated. (f) mRNA expression of TIGAR and p21 following $24 \mathrm{~h}$ of CDDP treatment $(50 \mu \mathrm{M})$ in $3 \mathrm{~T} 3 \mathrm{~s}$. Right: Graph represents quantification of western blots with fold change compared with untreated. Values represent mean \pm S.E.M. of three independent experiments unless otherwise indicated. ${ }^{*} P<0.05,{ }^{\star \star} P<0.005$ compared with untreated unless otherwise indicated. NS, not significant 
cells, we treated human tert-immortalised fibroblasts (TIFs) and mouse 3T3s with increasing concentrations of cisplatin (CDDP) to activate p53, but not induce cell death. After treatment, TIFs showed an increase in p53 protein level, along with an increased expression of TIGAR and a known p53 target, p21 (Figure 1c). However, although mouse 3T3s showed an elevation in p53 and p21, the expression of TIGAR was not detectably affected after treatment (Figure 1e). Similarly, using qRT-PCR to examine mRNA expression, human TIFs showed a significant increase in TIGAR mRNA expression after CDDP treatment that was not seen in the mouse cells (Figures 1d and f). These results suggest that p53 activation in mouse cells in culture does not consistently induce TIGAR expression.

Loss of p53 does not affect expression of TIGAR in vivo following IR. Previous work has shown that TIGAR expression levels are increased in the crypts of WT mice during intestinal regeneration following tissue ablation. ${ }^{11}$ As p53 is also upregulated in the small intestine following $I R,{ }^{21}$ we examined whether TIGAR expression is controlled by p53 in mice in vivo. The basal TIGAR protein levels were examined

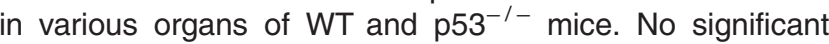
reduction in TIGAR expression was seen in response to loss of p53 at either the protein level (Figure 2a) or the mRNA level (Figure 2b) - with a possible exception of a slight reduction in TIGAR mRNA in p53-null muscle. By contrast, p21 showed a very clear decrease in mRNA expression in all the $\mathrm{p} 53^{-1-}$ organs examined.

To extend these studies, we tested whether a p53dependent increase in TIGAR expression would occur in vivo after damage, focusing on the intestinal system in which we have previously shown increased TIGAR in response to IR. Antibody specificity for TIGAR immunohistochemistry was confirmed using small intestine tissue from WT and TIGAR-deficient animals after treatment with IR to induce TIGAR expression. As shown previously, ${ }^{11}$ TIGAR expression increased in the crypts of WT mice following IR, whereas no staining was observed in $\mathrm{TIGAR}^{-1-}$ animals (Supplementary Figure 1b). Comparison of WT and $p 53^{-/-}$ mice showed normal crypt architecture and similar levels of proliferation, as indicated by Ki67 staining, under unstressed conditions (Figure 2c). The basal expression of p53, p21 and TIGAR was also low in the crypts of WT and $p 53^{-/-}$animals (Figure 2c). Tissue ablation of the intestinal epithelium by IR was followed by a period of recovery during which rapid tissue regeneration and proliferation occurred in WT and $\mathrm{p} 53^{-/-}$ mice. $^{22}$ Moreover, TIGAR expression increased in the crypts of both WT and $\mathrm{p} 53^{-1-}$ animals, whereas p21 induction was

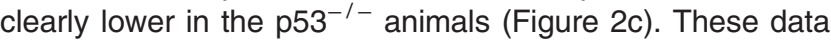
show that $p 53$ is not necessary to maintain basal expression of TIGAR in many tissues or induce TIGAR expression following tissue damage in the small intestine.

Comparison of human and mouse TIGAR p53-binding site activity. The in vitro and in vivo data suggest that murine TIGAR is only weakly responsive to p53, possibly due to the differences in p53-binding sites between human and mouse TIGAR (Figure 3a). To investigate the differences between the human (hBS1 and hBS2) and mouse
(mBS1 and mBS2) p53-binding sites of TIGAR directly, sequences corresponding to each p53-binding sites were cloned into infrared fluorescent protein (iRFP) reporter constructs. $^{23}$ These constructs were co-transfected into HCT116 $\mathrm{p5}^{-/-}$cells with increasing amounts of human or mouse p53 (Figures $3 b$ and c). Each of these p53-binding site reporters were activated by both human and mouse p53. TIGAR-hBS2, the more efficient of the two human p53-binding sites, is efficiently activated by either human or mouse p53 (Figure 3d). By contrast, TIGAR-mBS1 is more responsive to p53 than TIGAR-mBS2, and slightly more responsive than TIGAR-hBS1, although less active than TIGAR-hBS2. Interestingly, mouse p53 was slightly more effective in the induction of all the binding site reporters, with the exception of TIGARmBS2. Taken together, the results suggest that the weaker p53-binding site (BS1) is structurally and functionally conserved between mouse and human but the stronger BS2 in humans is only very weakly active in the mouse.

To determine whether p53 can bind to either of the two putative binding sites in the mouse Tigar promoter, chromatinimmunoprecipitation was carried out in mouse 3T3 cells treated with CDDP to activate p53 (Figure 3e). Although p53 was clearly recruited to the p21 promoter following treatment, no increased binding of p53 to either mBS1 or mBS2 could be detected in these cells. The failure to recruit p53 to the Tigar promoter can explain the observed inefficiency of p53dependent activation of mouse TIGAR expression seen in several cell types in vitro and in vivo.

TAp73a can activate the human TIGAR p53-binding site reporter. We further investigated the potential role of other p53 family members in the regulation of TIGAR expression. We first focused on the functional human p53-binding site (hBS2), co-transfecting the TIGAR-hBS2 iRFP reporter construct with p53, TAp63a or TAp73a to assess transcriptional activity. As positive controls we used iRFP expression constructs containing p53 response element encoding repeats of a known p53-binding sequence (p53RE), the p53-binding site of p21 (WAF1 $\left.{ }^{24}\right)$ and a p63 response element from the skin-specific promoter of bullous pemphigoid antigen $1\left(\mathrm{BPAG}_{1}{ }^{25}\right)$. Both TAp63 $a$ and TAp73 $a$ induced a response from the human TIGAR-hBS2 iRFP reporter construct, although the activity of TAp63a was extremely weak. The pattern of expression from TIGAR-hBS2 was similar to that seen with the p53RE or WAF1, where p53 was the most efficient, followed by TAp73a, then TAp63a. Strong activity for TAp63a was only measured using the BPAG1 promoter, although even here TAp73a was more active (Figures $4 a-c)$. In light of these results, we focused on TAp73 isoforms as potential activators of TIGAR expression.

The TAp73a isoform has been shown to contain an inhibitory domain that limits its activity, making it less efficient than other isoforms. ${ }^{26}$ We therefore examined the activity of p73 isoforms, TAp73a, TAp73 $\beta$, TAp73 $\gamma$ or $\Delta N p 73 a$, in these assays. Although full-length TAp73 isoforms can induce p53 target genes, ${ }^{27} \Delta \mathrm{Np} 73$ isoforms, which lack the $\mathrm{N}$-terminal activation domain, ${ }^{28}$ have been shown to inhibit TAp73 transcriptional activity as well as regulating an additional set of target genes. ${ }^{29}$ As expected, ${ }^{30,31}$ TAp73 $\beta$ was consistently more effective in driving expression from p53RE, WAF1 or 
a

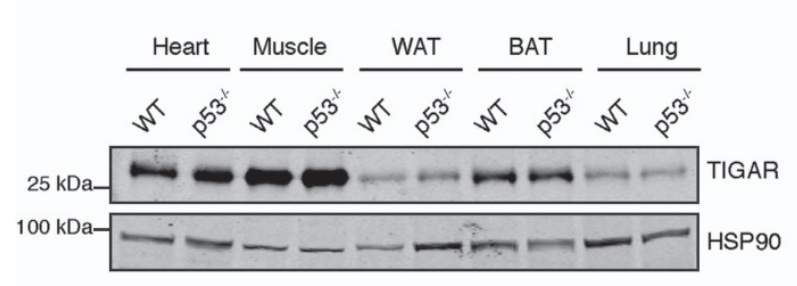

c

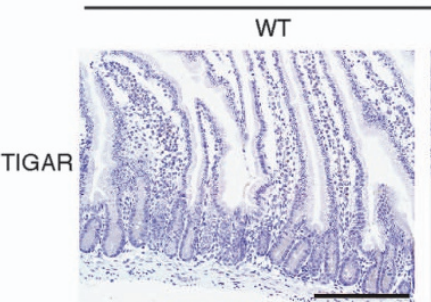

$0 \mathrm{hr}$
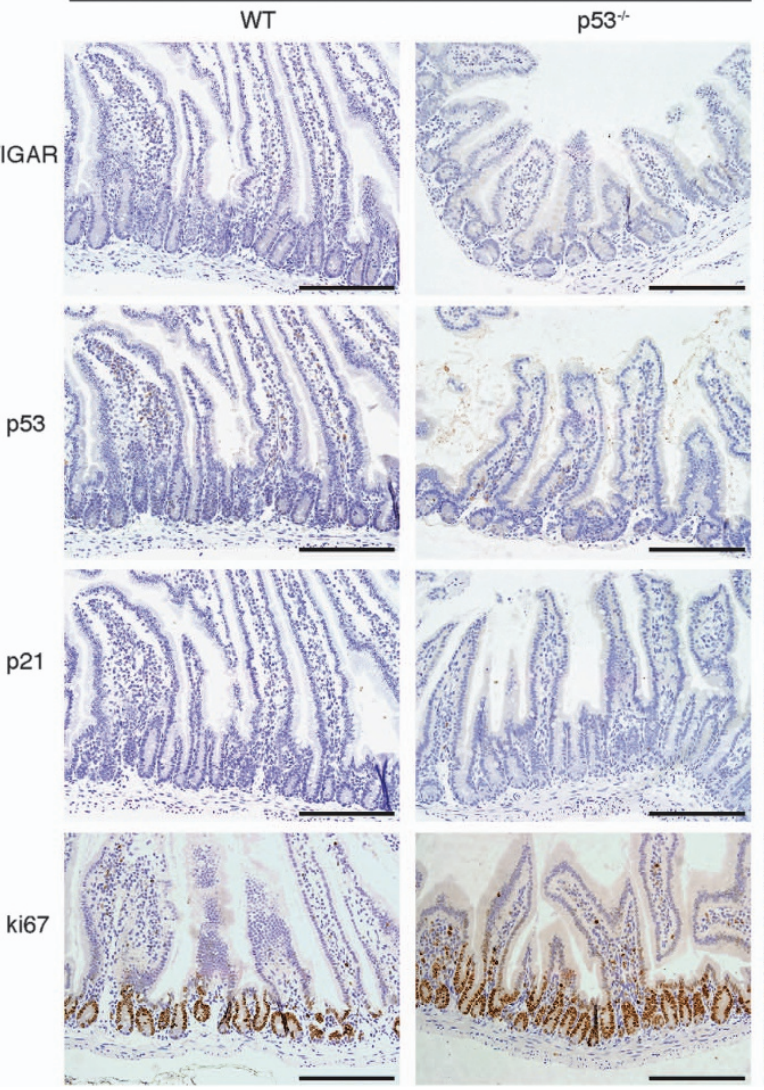
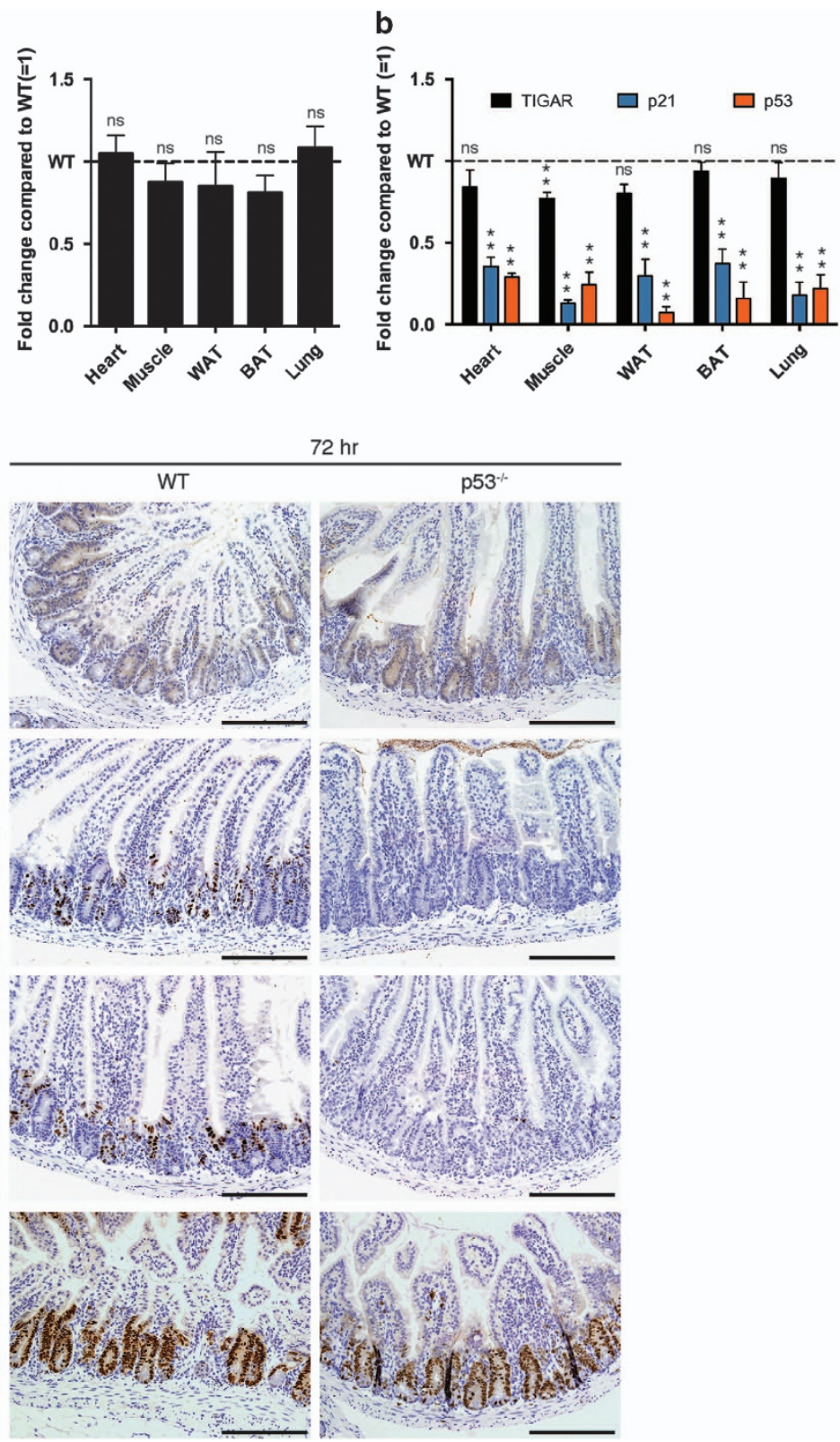

Figure 2 TIGAR expression in p53-null animals. (a) Left: Western blot analysis of TIGAR protein expression in organs of wild-type (WT) and p53 ${ }^{-1-}$ mice. Right: Graph represents quantification of western blots with fold change compared with WT. (b) mRNA expression of TIGAR, p21 and p53 in organs of WT and p53 ${ }^{-1-}$ mice. (c) Immunohistochemistry on small intestines from WT and p53 ${ }^{-1-}$ animals $72 \mathrm{~h}$ after $10 \mathrm{~Gy}$ IR. Scale bar, $20 \mu \mathrm{m}$. Values represent mean \pm S.E.M. of three independent experiments. ${ }^{*} P<0.05,{ }^{\star \star} P<0.005$ compared with WT. NS, not significant. WAT, white adipose tissue. BAT, brown adipose tissue

BPAG1 promoters. In these assays, TAp73 $\gamma$ and $\triangle \mathrm{Np} 73 a$ did not show strong transcriptional activity. Turning to the reporter constructs containing TIGAR p53-binding sites (hBS2, mBS1 and mBS2), we found that TAp73a more effectively induced expression from hBS2, whereas both TAp73a and TAp73 $\beta$ modestly induced expression from mBS1 and mBS2 (Figures 4d-f). Taken together, the data suggest that like p53, TAp73 has the potential to drive the expression of both mouse and human TIGAR.

Loss of TAp73 does not affect expression of TIGAR in vivo following IR. p73 can be activated by DNA damage, ${ }^{32-34}$ potentially mediating the induction of TIGAR expression in response to IR independently of p53. To investigate this, we examined TIGAR expression in TAp73deficient $\left(\mathrm{TAp}_{73^{-/-}}\right)$mice. First, the basal expression of TIGAR was assessed in various organs of untreated WT and $\mathrm{TAp}^{-1-}$ mice (Figure 5a). As seen in $\mathrm{p} 53^{-1-}$ mice, no clear significant decrease in TIGAR expression was seen in $\mathrm{TAp}_{73^{-1}}$ tissues, with a possible small reduction in protein and mRNA levels in the muscle (Figure 5b). Following IR, intestines of $\mathrm{TAp}^{-1-}$ mice underwent rapid proliferation, as shown by the proliferative marker Ki67 (Figure 5c). Although induction of TAp73 was limited to the WT mice, TIGAR expression was increased in the crypts of both WT and $\mathrm{TAp} 3^{-/-}$animals, showing that this induction of expression 
a
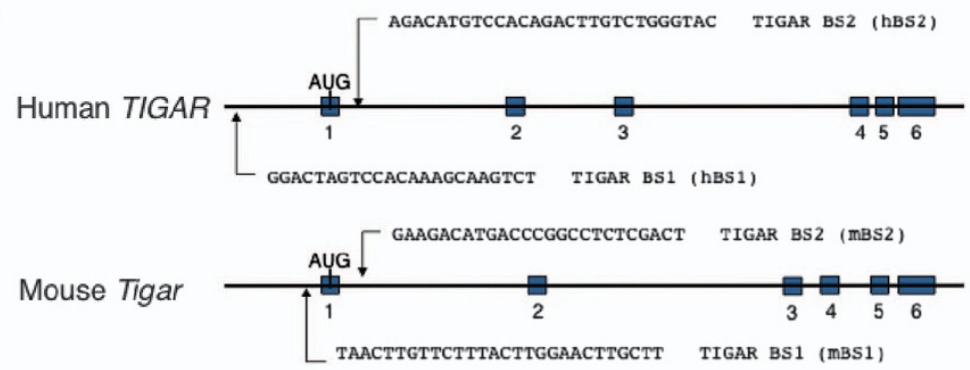

b
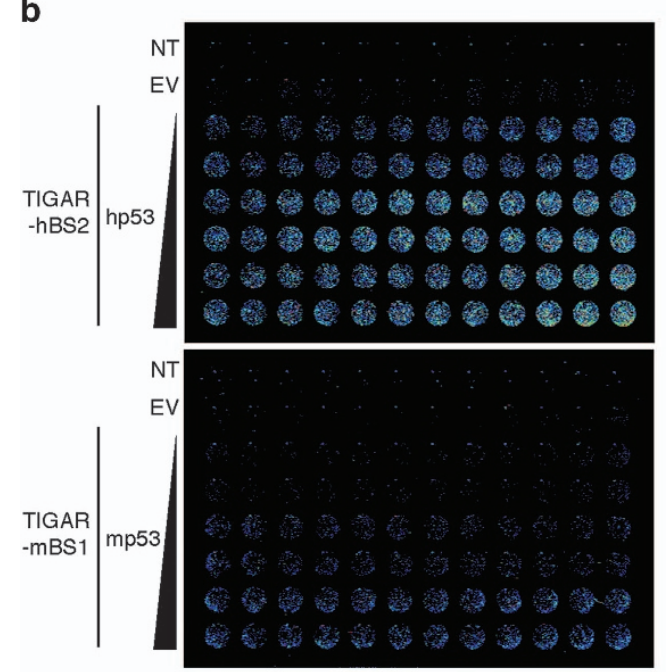

d

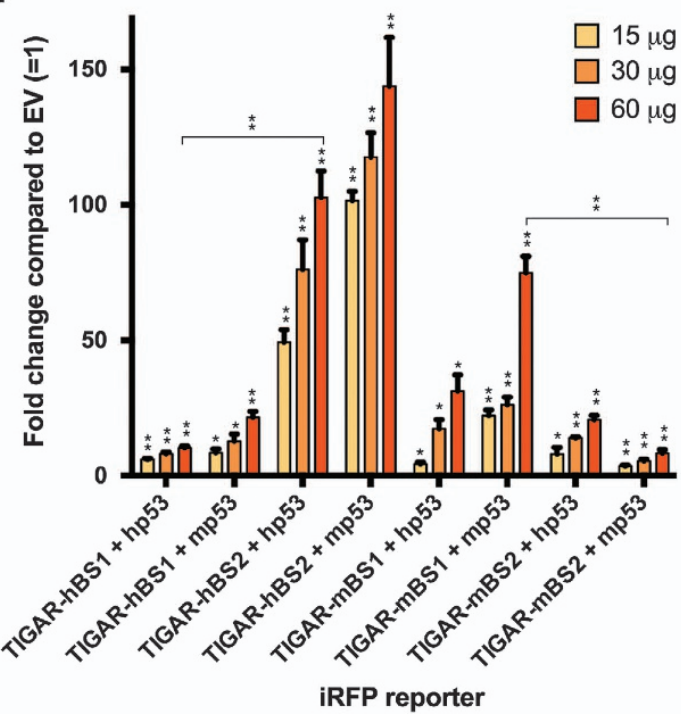

c

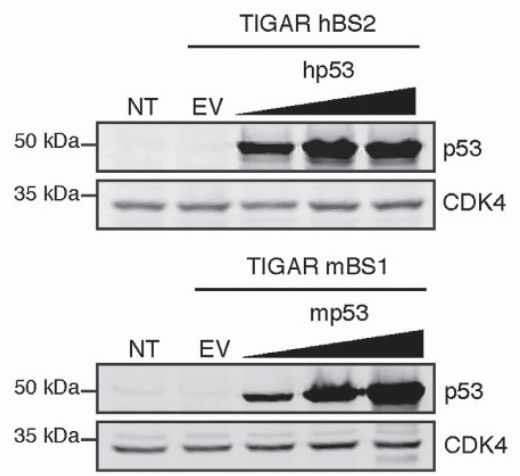

e

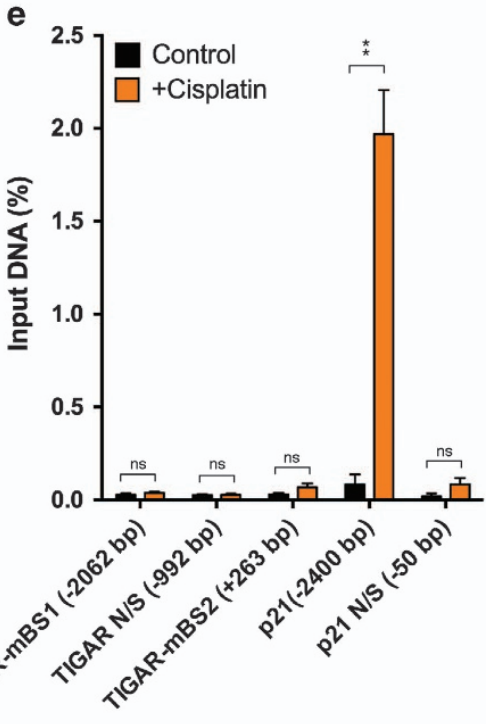

Figure 3 Comparison of human and mouse p53-binding sites on the TIGAR promoter. (a) Possible p53-binding sites along human and mouse TIGAR. (b) Representative iRFP reporter assay scan of HCT116 $\mathrm{p} 53^{-1-}$ cells $24 \mathrm{~h}$ after co-transfection with TIGAR-hBS2 or TIGAR-mBS1 iRFP reporter and increasing amounts of human p53 or mouse p53. (c) Western blot analysis of HCT116 p53 $3^{-1-}$ cells transfected with increasing amounts of human p53 or mouse p53. (d) Quantification of iRFP reporter scans on human (hBS1 and hBS2) and mouse (mBS1 and mBS2) TIGAR promoter-binding sites with increasing levels of human or mouse p53. (e) Chromatin-immunoprecipitation (ChIP) was performed for p53 with quantitative PCR for mBS1 (-2062 bp), mBS2 (+263 bp), a p53 response element on the p21 promoter ( $-2400 \mathrm{bp}$ ) and non-specific (N/S) binding regions on the Tigar ( $-992 \mathrm{bp})$ and $p 21$ promoter $(-50 \mathrm{bp})$, using $3 \mathrm{~T} 3 \mathrm{~s}$ treated with $50 \mu \mathrm{M}$ cisplatin for $24 \mathrm{~h}$. Values represent mean \pm S.E.M. of three independent experiments. ${ }^{*} P<0.05,{ }^{* *} P<0.005$ compared with empty vector (EV) or control. NT, non-transfected; NS, not significant 
a

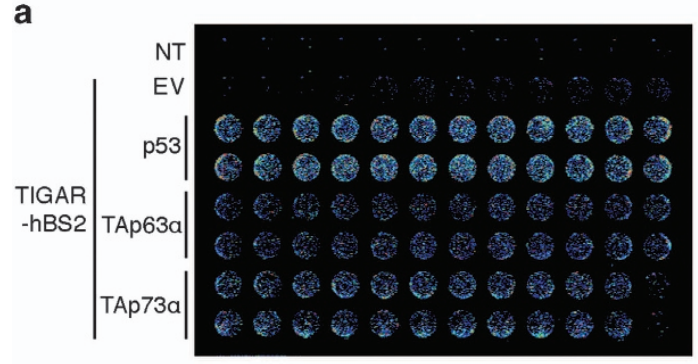

b

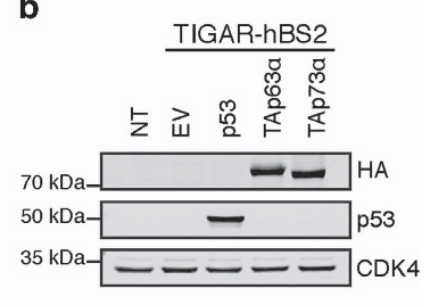

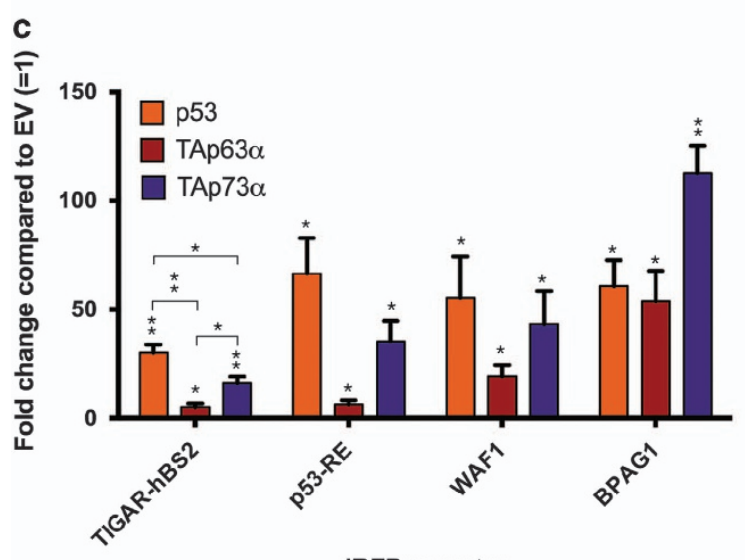

iRFP reporter

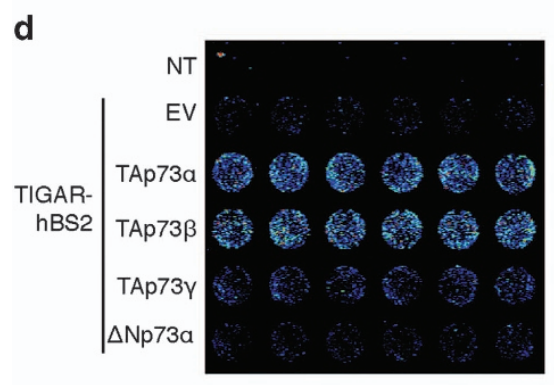

e
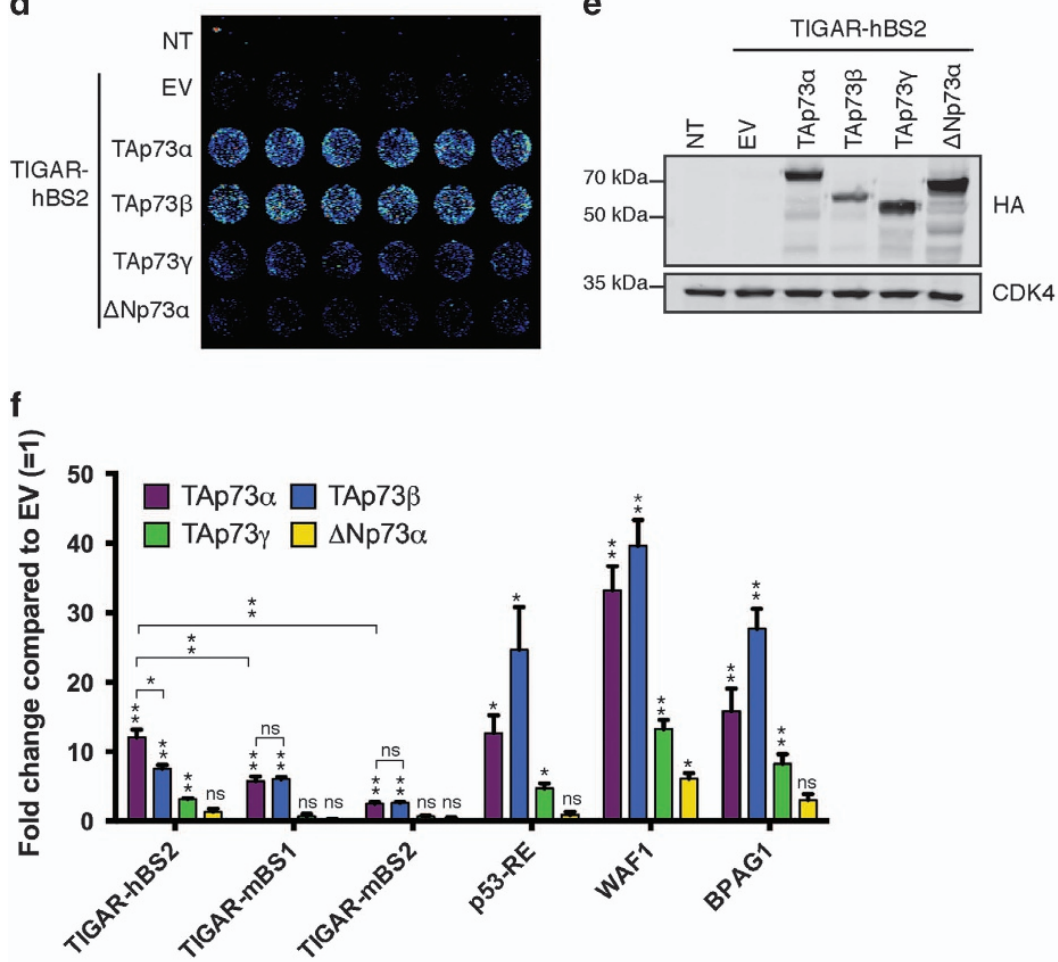

iRFP reporter

Figure 4 TAp63 $\alpha$ and TAp73 $\alpha$ can activate the TIGAR-hBS2 reporter. (a) Representative iRFP reporter assay scan of HCT116 $\mathrm{p5} 3^{-1-}$ cells $24 \mathrm{~h}$ after co-transfection with TIGAR-hBS2 iRFP reporter along with human p53, HA-tagged TAp63 $\alpha$ or HA-tagged TAp73 $\alpha$. (b) Western blot analysis of HCT116 p53 ${ }^{-1}$ - cells with transfected p53, HA-tagged TAp63 $\alpha$ or HA-tagged TAp73 $\alpha$. (c) Quantification of iRFP reporter scans. (d) Representative iRFP reporter assay scan of HCT116 p53-l- cells $24 \mathrm{~h}$ after co-transfection with TIGAR-hBS2 iRFP reporter along with TAp73 $\alpha$, TAp73 $\beta$, TAp73 $\gamma$ or $\Delta$ Np73 $\alpha$. (e) Western blot analysis of HCT116 p53-1- cells with transfected HA-tagged TAp73 $\alpha$, HA-tagged TAp73 $\beta$, HA-tagged TAp73 $\gamma$ or HA-tagged $\Delta$ Np73 $\alpha$. (f) Quantification of iRFP reporter scans on human (hBS2) and mouse (mBS1 and mBS2) TIGAR promoter-binding sites. Values represent mean \pm S.E.M. of three independent experiments. ${ }^{*} P<0.05,{ }^{* \star} P<0.005$ compared with empty vector (EV). NT, non-transfected; NS, not significant 


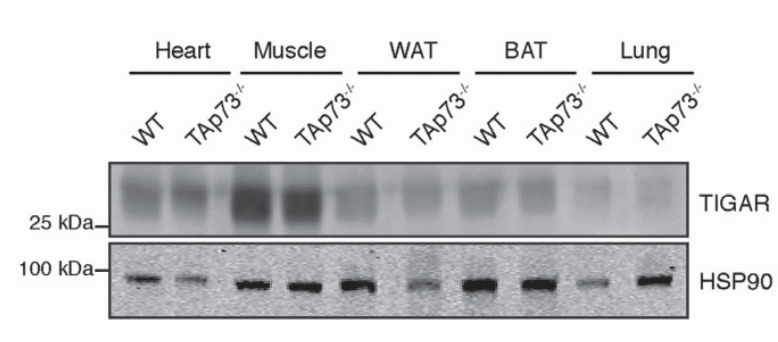

C

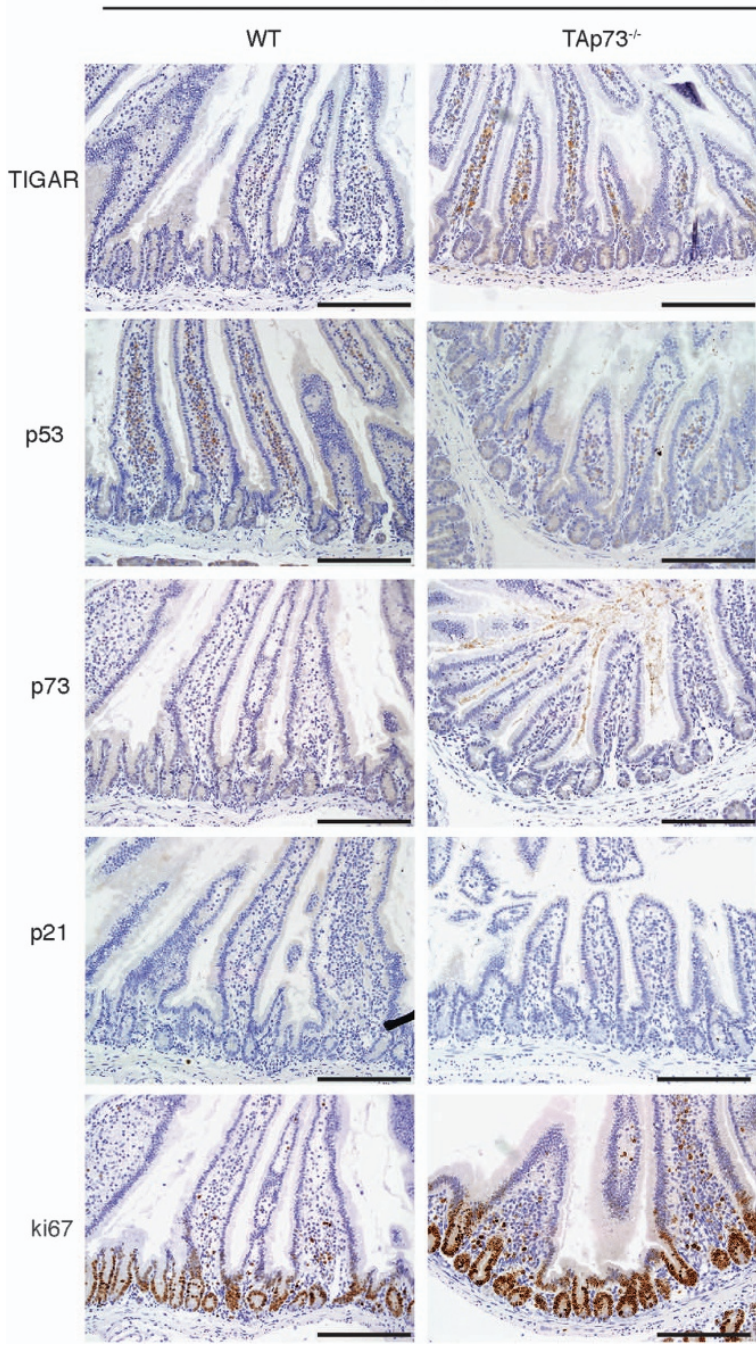

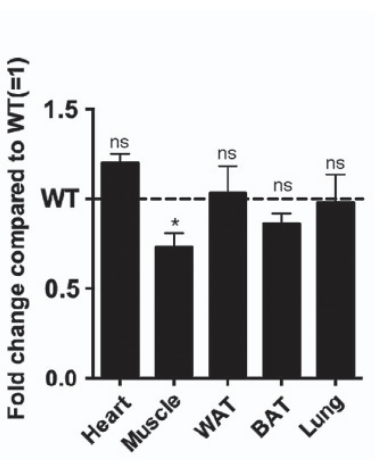

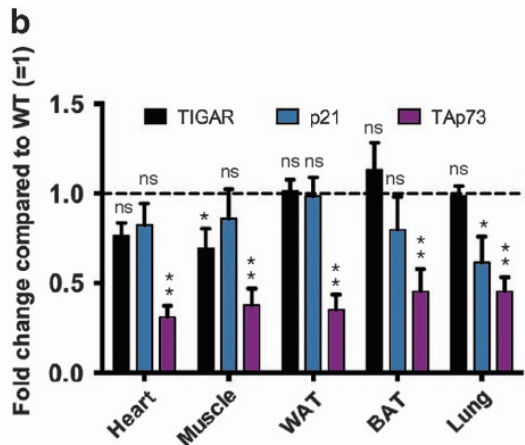

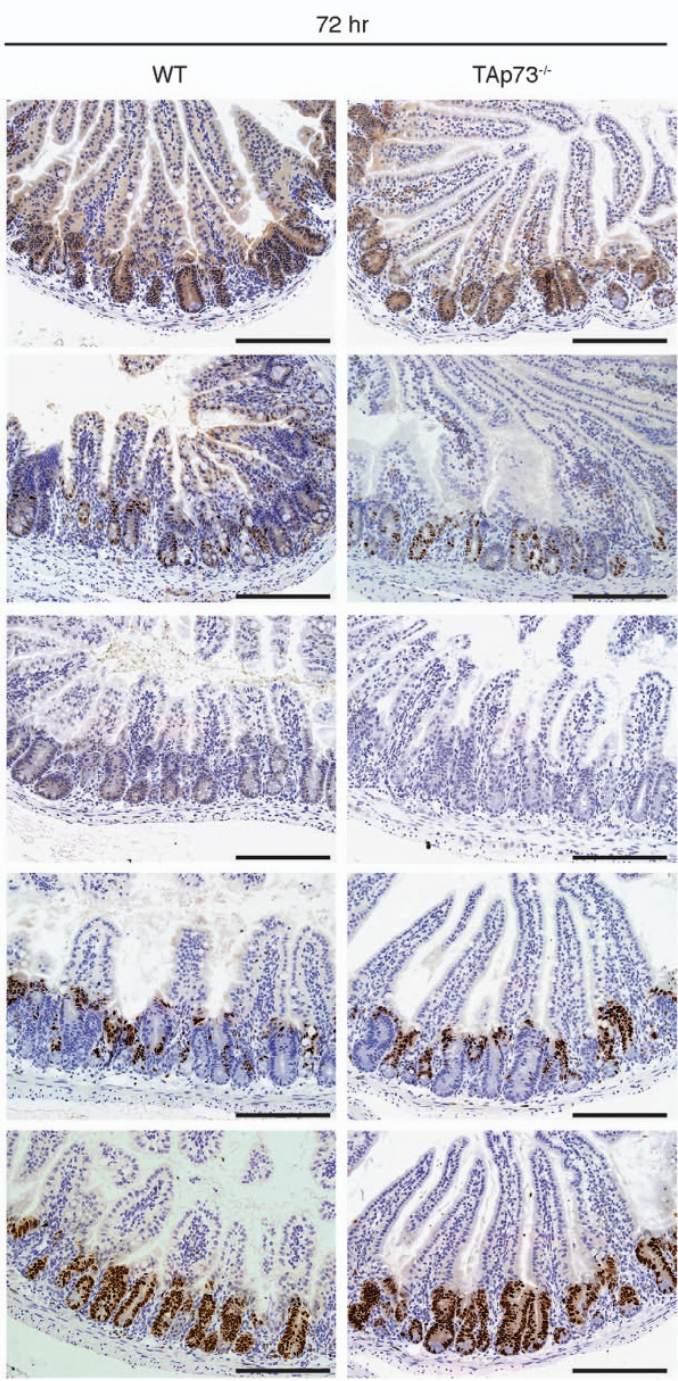

Figure 5 TIGAR expression in TAp73-null animals. (a) Left: Western blot analysis of TIGAR protein expression in organs of wild-type (WT) and TAp73 ${ }^{-1-}$ mice. Right: Graph represents quantification of western blots with fold change compared with WT. (b) mRNA expression of TIGAR, p21 and TAp73 in organs of WT and TAp73 $3^{-1-}$ mice. (c) Immunohistochemistry on small intestines from WT and TAp73 ${ }^{-1-}$ animals $72 \mathrm{~h}$ after $10 \mathrm{~Gy}$ IR. Scale bar, $20 \mu \mathrm{m}$. Values represent mean \pm S.E.M. of three independent experiments. ${ }^{*} P<0.05,{ }^{\star}{ }^{\star} P<0.005$ compared with WT. NS, not significant; WAT, white adipose tissue; BAT, brown adipose tissue

was not dependent on TAp73. p21 levels were also induced, reflecting the accumulation of p53 in response to IR in the $\mathrm{TAp}^{-l-}$ animals (Figure $5 \mathrm{c}$ ).

Finally, we examined possible redundancy between p53 and TAp73 in the induction of TIGAR expression after $\mathrm{IR}$, by examining the effect of simultaneous deletion of both transcription factors. Compared with WT animals, there was no significant decrease in TIGAR expression in the organs of $\mathrm{p} 53^{-1-} \mathrm{TAp} 73^{-1-}$ mice (Figure 6a). Intestinal tissue from both WT and $\mathrm{p} 53^{-1-} \mathrm{TAp} 73^{-1-}$ animals showed a similar increase in TIGAR protein expression following IR that was detected by western blot of tissue samples 
a

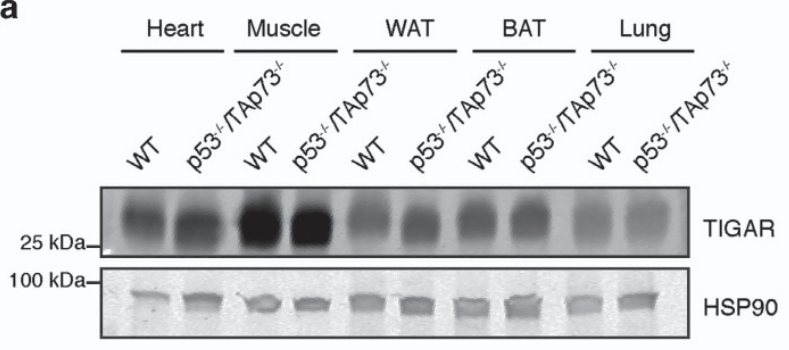

C
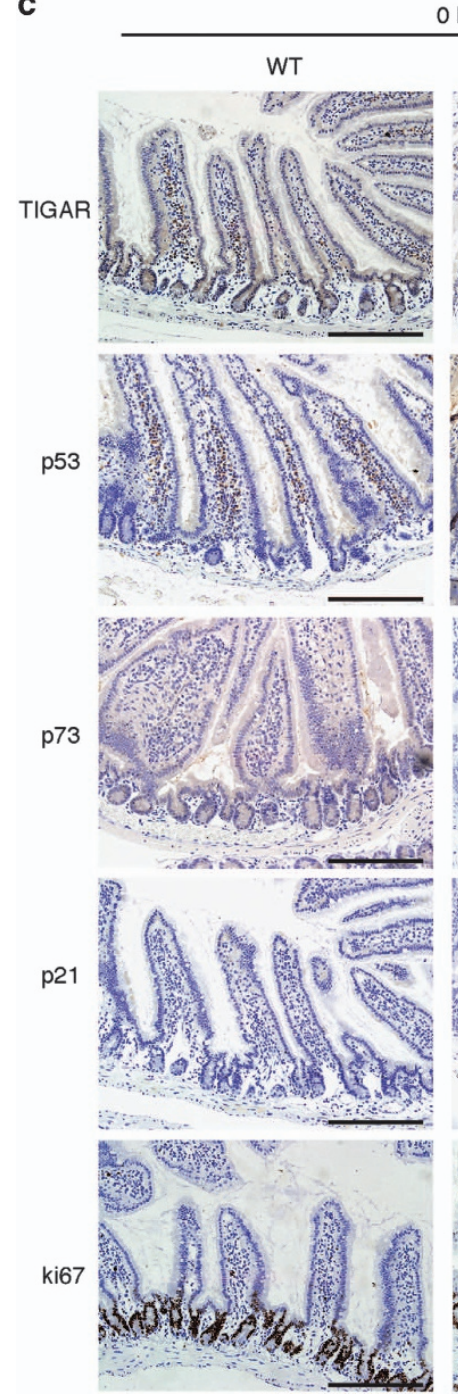

$\mathrm{O} \mathrm{hr}$
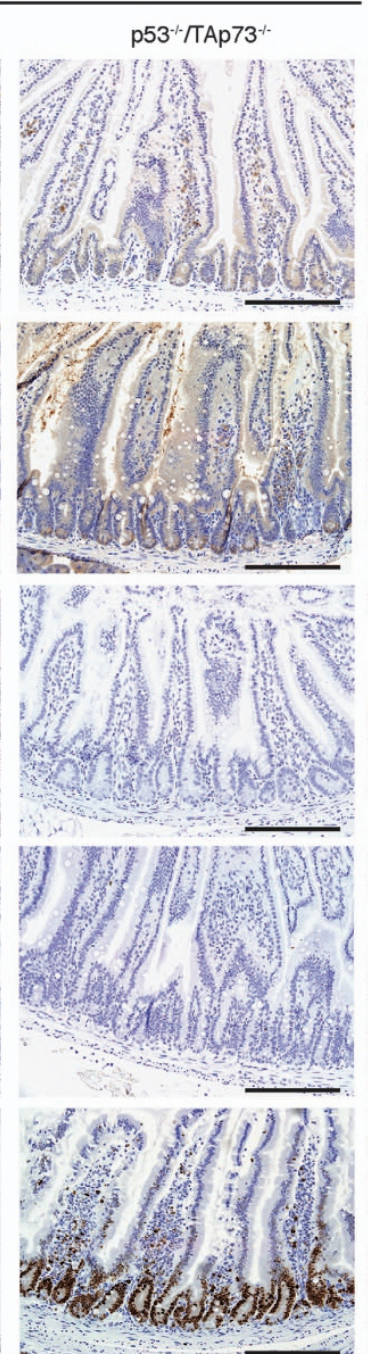

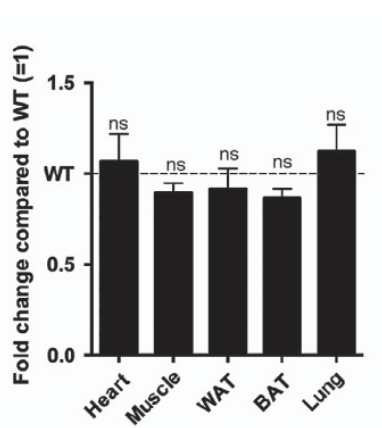

b

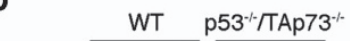

$25 \mathrm{kDa} \rightleftharpoons$ TIGAR

$100 \mathrm{kDa}-\mathrm{HSP9O}$
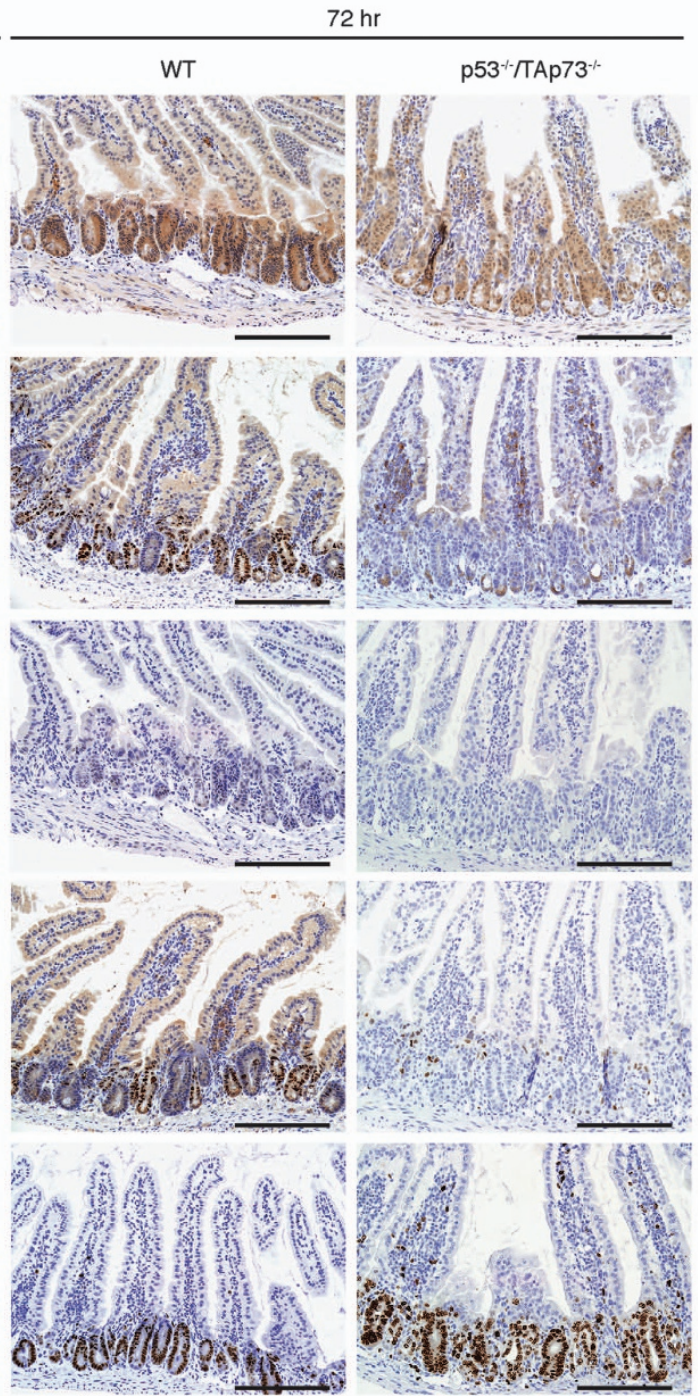

Figure 6 TIGAR expression in p53- and TAp73-null animals. (a) Left: Western blot analysis of TIGAR protein expression in organs of wild-type (WT) and p53 ${ }^{-1-}$ TAp73 ${ }^{-/-}$ mice. Right: Graph represents quantification of western blots with fold change compared with WT. (b) Western blot analysis of TIGAR protein expression in small intestine tissue of

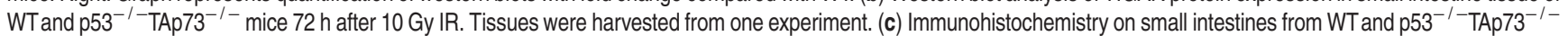
animals $72 \mathrm{~h}$ after $10 \mathrm{~Gy}$ IR. Scale bar, $20 \mu \mathrm{m}$. Values represent mean \pm S.E.M. of two independent experiments unless otherwise indicated. NS, not significant; WAT, white adipose tissue; BAT, brown adipose tissue

or IHC of crypts (Figures $6 \mathrm{~b}$ and c). Taken together, these data show that the increase in TIGAR expression seen following IR and gut regeneration is not dependent on p53 or TAp73 in mouse.

\section{Discussion}

We have previously shown that TIGAR is induced following IRinduced intestinal damage and supports regeneration in the mouse. In humans, TIGAR is a p53 target gene and found to 
have a role in conditions of mild stress to promote cell survival. ${ }^{2,5}$ We showed here that TAp73 can also activate expression from the TIGAR promoter in human cells. As IR can activate both $p 53^{21}$ and TAp73, ${ }^{32-34}$ we sought to test the hypothesis that the increase in TIGAR seen in mouse intestine following IR is a response to p53 and/or TAp73.

Our studies in cultured cells did not show a clear p53dependent increase in TIGAR expression in mouse cells. A closer examination of the transcriptional control regions of human and mouse TIGAR showed that the principal p53responsive element in human TIGAR is not well conserved in mouse TIGAR and is much less responsive to p53. The second, weaker binding site in humans seems to be conserved and somewhat more responsive to p53 in mouse. However, overall, the p53-binding sites in the human TIGAR promoter appear to be more responsive than those found in the mouse. TAp73 was also able to activate expression of mouse and human TIGAR-binding site reporters.

Despite the potential for both p53 and TAp73 to activate TIGAR expression, we found that although basal levels of TIGAR expression vary significantly between different mouse tissues, they are generally not affected by the loss of p53 or TAp73. Furthermore, the induction of TIGAR in mouse small intestine in response to IR does not depend on p53 or TAp73. Mice deficient for both $\mathrm{p} 53$ and TAp73 maintain a similar basal expression of TIGAR to WT animals and retain the ability to upregulate the expression of TIGAR in the crypts of the small intestine following tissue ablation. Importantly, several previous studies have shown p53-responsive expression of TIGAR in mouse cells and tissues such as the liver and heart, and $p 53$ binding to the Tigarpromoter was also detected in the liver. ${ }^{10,18-20}$ We also found a significant, but minor, reduction in TIGAR expression in p53 or TAp73-deficient muscle (Figures 2 and 5). Taken together, the data suggest that although p53 can induce TIGAR in some mouse tissues, the p53-responsiveness of mouse TIGAR expression is lower than observed in human cells. To some extent this difference reflects the binding of $p 53$ to the different response elements in the mouse and human TIGAR-encoding genes. However, it is also possible that tissue or stress-specific co-factors (that may show human/mouse differences in expression or availability) are required to allow p53 regulation of TIGAR expression. Given the function of TIGAR as a regulator of metabolism, it will be of particular interest to see whether p53 family proteins with other co-factors can participate in the induction of TIGAR in response to different forms of metabolic stress.

TIGAR has been found to be elevated in several human tumour types. ${ }^{4,11,12}$ The expression of TIGAR under these conditions does not correlate with the maintenance of WT p53, ${ }^{13}$ suggesting that TIGAR overexpression in tumours can be uncoupled from the activity of p53. Our data show that mouse TIGAR expression is also regulated through p53independent mechanisms, and is strongly activated in intestinal crypts following IR and APC deletion. ${ }^{11}$ These observations suggest that activation of the Wnt signalling pathway may contribute to the regulation of TIGAR, particularly in the small intestine where this pathway has a key role in cell proliferation. Moreover, other transcription factors such as SP1 and $C R E B^{14,15}$ have been shown to have a role in regulating the basal expression of TIGAR in liver cancer cell lines. Future studies will be required to establish how TIGAR expression is regulated during stress and whether deregulation of these pathways explains the elevated expression of TIGAR seen in human tumours.

\section{Materials and Methods}

Cell culture. All cell lines were cultured in Dulbecco's modified Eagle's medium (DMEM) supplemented with $10 \%$ of fetal bovine serum, $1 \%$ of glutamine, $1 \%$ of penicillin/streptomycin (Life Technologies, Paisley, UK), grown in a $37^{\circ} \mathrm{C}$ incubator at $5 \% \mathrm{CO}_{2}$. CDDP (Sigma-Aldrich, St. Louis, MO, USA) was used at the indicated concentrations and times.

Small intestinal crypt culture. Small intestinal crypt culture was performed as previously described. ${ }^{35}$ Small intestine was washed in cold PBS and villi were scraped off using a glass coverslip. The small intestine was then cut into small pieces and further washed in cold PBS. This was then transferred into PBS containing $2 \mathrm{mM}$ EDTA and incubated for $30 \mathrm{~min}$. Crypts were then obtained via mechanical pipetting and the supernatant containing the crypts was collected. The crypts were centrifuged at a low speed (700 r.p.m., $3 \mathrm{~min}$ ) to remove single cells and the final pellet was resuspended in growth factor reduced Matrigel (BD, Franklin Lakes, NJ, USA). Crypts were cultured in Advanced DMEM/F-12 (Life Technologies) supplemented with $1 \%$ of glutamine, $1 \%$ of penicillin/streptomycin, $0.1 \%$ of AlbuMAX I (Life Techologies), $10 \mathrm{mM}$ HEPES (Life Technologies), $0.05 \mu \mathrm{g} / \mathrm{ml}$ EGF (Peprotech, Rockyhill, NJ, USA), $0.1 \mu \mathrm{g} / \mathrm{ml}$ Noggin (Peprotech) and $0.5 \mu \mathrm{g} / \mathrm{ml} \mathrm{mR}$ spondin (R\&D Systems, Minneapolis, MN, USA).

Animals. All animal work was carried out in-line with the Animals (Scientific Procedures) Act 1986 and the EU Directive 2010 and sanctioned by Local Ethical Review Process (University of Glasgow). The $\mathrm{p} 53^{-/-36}$ and $\mathrm{TAp}^{-1-37}$ animals have been previously described.

Western blot. Cell lysates were prepared in RIPA buffer with complete protease inhibitors (Roche, Penzberg, Germany), resolved via PAGE and transferred to nitrocellulose membranes. The following primary antibodies were used: Actin I-19- R (Santa Cruz Biotechnology, Dallas, TX, USA), cyclin D1 (Cell Signalling Technology, Danvers, MA, USA), CDK4 C-22 (Santa Cruz Biotechnology), HA.11 $16 \mathrm{~B} 12$ (Covance, Princeton, NJ, USA), HSP90 (Cell Signalling Technology), p21 C-19 (Santa Cruz Biotechnology), p53 1C12 (Cell Signalling Technology), p53 DO-1 (Santa Cruz Biotechnology), TIGAR G-2 (Santa Cruz Biotechnology) and TIGAR M-209 (Santa Cruz Biotechnology). Secondary antibodies were IRDye800CWconjugated (LiCor Biosciences, Lincoln, NE, USA) and detection was performed using an Odyssey infrared scanner (LiCor Biosciences).

Gene expression analyses. RNA was isolated from cells or mouse tissue using the RNeasy RNA Isolation kit according to the manufacturer's instructions (Qiagen, Valencia, CA, USA). Mouse TIGAR primer was purchased from Qiagen and mouse GAPDH was used as murine housekeeping gene (Primer Design, Southampton, UK).

mRNA primer sequences $\left(5^{\prime} \rightarrow 3^{\prime}\right)$ :
Human TIGAR for

Human TIGAR rev

Human p21 for

Human p21 rev

Human p53 for

Human p53 rev

Human RPLPO for

Human RPLPO rev

Mouse p21 for

Mouse p21 rev

Mouse p53 for

Mouse TAp73 for

Mouse TAp73 rev
Mouse p53 rev
CGGCATGGAGAAAGAAGATT TCCTTTCCCGAAGTCTTGAG CTGGAGACTCTCAGGGTCGAAA GATTAGGGCTTCCTCTTGGAGAA CCCTTCCCAGAAAACCTACC CTCCGTCATGTGCTGTGACT GCAATGTTGCCAGTGTCTG GCCTTGACCTTTTCAGCAA GGCCCGGAACATCTCAGG AAATCTGTCAGGCTGGTCTGC CACGTACTCTCCTCCCCTCAAT AACTGCACAGGGCACGTCTT GCACCTACTTTGACCTCCCC GCACTGCTGAGCAAATTGAAC
IR treatment. Gamma IR-induced intestinal damage was performed as previously described. ${ }^{38}$ 
Immunohistochemistry. Immunohistochemistry was performed as previously described. ${ }^{39}$ Primary antibodies used were: TIGAR (Merck Millipore, Darmstadt, Germany), p53 CM-5 (Vector Laboratories, Peterborough, UK), p21 M-19 (Santa Cruz Biotechnology), p73 S-20 (Santa Cruz Biotechnology) and Ki67 (Thermo Scientific, Waltham, MA, USA).

Plasmids. pcDNA3.1+ (Invitrogen, Grand Island, NY, USA) was used as empty vector control. iRFP reporter constructs were generated as previously described. ${ }^{23}$ Reporter elements were ligated into vectors using the InFusion HD Eco Dry system (Clontech, Saint-Germain-en-Laye, France) according to the manufacturer's instructions.

Insert primer sequences $\left(5^{\prime} \rightarrow 3^{\prime}\right)$ :

\begin{tabular}{|c|c|}
\hline & \\
\hline $\begin{array}{l}\text { TIGAR hBS1 for } \\
\text { TIGAR hBS1 rev }\end{array}$ & $\begin{array}{l}\text { GGACTAGTCCACAAAGCAAGTCT } \\
\text { AGACTTGCTTTGTGGACTAGTCC }\end{array}$ \\
\hline TIGAR-hBS2 for & AGACATGTCCACAGACTTGTCTGGGTAC \\
\hline TIGAR-hBS2 rev & GTACCCAGACAAGTCTGTGGACATGTCT \\
\hline TIGAR-mBS1 for & TAACTTGTTCTTTACTTGGAACTTGCTT \\
\hline TIGAR-mBS1 rev & AAGCAAGTTCCAAGTAAAGAACAAGTTA \\
\hline TIGAR-mBS2 for & GAAGACATGACCCGGCCTCTCGACT \\
\hline & AGTCGAGAGGCCGGGTCATGTCTTC \\
\hline 53RF f & $\begin{array}{l}\text { GGACATGCCCGGGCATGTCCCCAGAGACAT } \\
\text { GTCCAGACATGTCCCCAGGAACATGTCCCAA } \\
\text { CATGTTGTCCAGGAGACATGTCCAGACATGTC } \\
\text { CCCAGGAACATGTCCCAACATGTTGT }\end{array}$ \\
\hline p53RE rev & $\begin{array}{l}\text { ACAACATGTTGGGACATGTTCCTGGGGACATG } \\
\text { TCTGGACATGTCTCCTGGACAACATGTTGGGA } \\
\text { CATGTTCCTGGGGACATGTCTGGACATGTCTC } \\
\text { TGGGGACATGCCCGGGCATGTCC }\end{array}$ \\
\hline WAF1 for & GAACATGTCCCAACATGTTG \\
\hline WAF1 rev & CAACATGTTGGGACATGTTC \\
\hline BPAG1 for & $\begin{array}{l}\text { CGCCATGCATGAATTCCGCGTTCTGCCTGCT } \\
\text { TTGTTCATACTTGTAGGCACTAGTTAGGCGTGTA }\end{array}$ \\
\hline BPAG1 & $\begin{array}{l}\text { TACACGCCTAACTAGTGCCTACAAGTATGAACA } \\
\text { AAGCAGGCAGAACGCGGAATTCATGCATGGCG }\end{array}$ \\
\hline
\end{tabular}

Transient transfections and irfp reporter assays. Cells were seeded on 6-well plates for protein expression analysis or 96-well CellBIND clear bottom black microplates (Corning, Corning, NY, USA) for iRFP reporter assays and grown overnight prior to being transfected using GeneJuice (Merck Millipore) according to the manufacturer's manual. Twenty-four hours after co-transfection, cells were harvested as described above for protein expression analysis or scanned using an Odyssey infrared scanner (LiCor Biosciences). For quantification, plates were scanned at $169 \mu \mathrm{M}$ resolution, $3.5 \mathrm{~mm}$ offset and a low-intensity setting. ${ }^{23}$

Chromatin-immunoprecipitation. Assays were performed as previously described ${ }^{40}$ Cells were seeded in a $10-\mathrm{cm}$ plate in DMEM and allowed to grow for $24 \mathrm{~h}$ before treatment with CDDP for $24 \mathrm{~h}$.

Quantification and statistical analysis. Image Studio software (LiCor, V2.1.10) was used to quantify western blots as well as iRFP reporter assays on 96well plates. The data represent mean values \pm S.E.M. from at least three independent experiments $(n=3)$ unless otherwise noted. All $P$ values were obtained using a t-test.

\section{Conflict of Interest}

The authors declare no conflict of interest.

Acknowledgements. We are extremely thankful to Dimitris Athineos and Karen Blyth for providing p53 and TAp73 null mice, Cancer Research UK Glasgow Centre (C596/A18076), Cancer Research UK Beatson Institute Biological Services (C596/A17196) and Histology Service for technical assistance. We also acknowledge generous funding from Cancer Research UK grant C596/A10419, ERC Grant 322842-METABOp53 and an MRC studentship.

1. Lee P, Vousden KH, TIGAR Cheung EC. TIGAR, burning bright. Cancer Metab 2014; 2 : 1. 2. Bensaad K, Tsuruta A, Selak MA, Vidal MN, Nakano K, Bartrons R et al. TIGAR, a p53inducible regulator of glycolysis and apoptosis. Cell 2006; 126: 107-120.
3. Cheung EC, Ludwig RL, Vousden KH. Mitochondrial localization of TIGAR under hypoxia stimulates HK2 and lowers ROS and cell death. Proc Natl Acad Sci USA 2012; 109: 20491-20496.

4. Wanka C, Steinbach JP, Rieger J. Tp53-induced glycolysis and apoptosis regulator (TIGAR) protects glioma cells from starvation-induced cell death by up-regulating respiration and improving cellular redox homeostasis. J Biol Chem 2012; 287 33436-33446.

5. Bensaad K, Cheung EC, Vousden KH. Modulation of intracellular ROS levels by TIGAR controls autophagy. The EMBO J 2009; 28: 3015-3026.

6. Yin L, Kosugi M, Kufe D. Inhibition of the MUC1-C oncoprotein induces multiple myeloma cell death by down-regulating TIGAR expression and depleting NADPH. Blood 2012; 119: 810-816.

7. Lui VW, Wong EY, Ho K, Ng PK, Lau CP, Tsui SK et al. Inhibition of c-Met downregulates TIGAR expression and reduces NADPH production leading to cell death. Oncogene 2011; 30: $1127-1134$

8. Li M, Sun M, Cao L, Gu JH, Ge J, Chen J et al. A TIGAR-regulated metabolic pathway is critical for protection of brain ischemia. J Neurosci 2014; 34: 7458-7471.

9. Gerin I, Noel G, Bolsee J, Haumont O, Van Schaftingen E, Bommer GT. Identification of TP53-induced glycolysis and apoptosis regulator (TIGAR) as the phosphoglycolateindependent 2,3-bisphosphoglycerate phosphatase. Biochem J 2014; 458: 439-448.

10. Hamard PJ, Barthelery N, Hogstad B, Mungamuri SK, Tonnessen CA, Carvajal LA et al. The $\mathrm{C}$ terminus of $\mathrm{p} 53$ regulates gene expression by multiple mechanisms in a target- and tissuespecific manner in vivo. Genes Dev 2013; 27: 1868-1885.

11. Cheung EC, Athineos D, Lee $P$, Ridgway RA, Lambie W, Nixon $C$ et al. TIGAR is required for efficient intestinal regeneration and tumorigenesis. Dev Cell 2013; 25: 463-477.

12. Sinha S, Ghildiyal R, Mehta VS, Sen E. ATM-NFkappaB axis-driven TIGAR regulates sensitivity of glioma cells to radiomimetics in the presence of TNFalpha. Cell Death Dis 2013; 4: e615.

13. Won KY, Lim SJ, Kim GY, Kim YW, Han SA, Song JY et al. Regulatory role of p53 in cancer metabolism via SCO2 and TIGAR in human breast cancer. Hum Pathol 2012; 43: 221-228.

14. Zou S, Gu Z, Ni P, Liu X, Wang J, Fan Q. SP1 plays a pivotal role for basal activity of TIGAR promoter in liver cancer cell lines. Mol Cell Biochem 2012; 359: 17-23.

15. Zou S, Wang X, Deng L, Wang Y, Huang B, Zhang N et al. CREB, another culprit for TIGAR promoter activity and expression. Biochem Biophys Res Commun 2013; 439: 481-486.

16. Lee CW, La Thangue NB. Promoter specificity and stability control of the p53-related protein p73. Oncogene 1999; 18: 4171-4181.

17. Yang $A$, Kaghad $M$, Wang $Y$, Gillett E, Fleming MD, Dotsch V et al. p63, a p53 homolog a 3q27-29, encodes multiple products with transactivating, death-inducing, and dominantnegative activities. Mol Cell 1998; 2: 305-316.

18. Li T, Kon N, Jiang L, Tan M, Ludwig T, Zhao $Y$ et al. Tumor suppression in the absence of p53-mediated cell-cycle arrest, apoptosis, and senescence. Cell 2012; 149: 1269-1283.

19. Kimata M, Matoba S, Iwai-Kanai E, Nakamura H, Hoshino A, Nakaoka M et al. p53 and TIGAR regulate cardiac myocyte energy homeostasis under hypoxic stress. Am J Physiol Heart Circ Physiol 2010; 299: H1908-H1916.

20. Hoshino A, Matoba S, Iwai-Kanai E, Nakamura H, Kimata M, Nakaoka M et al. p53-TIGAR axis attenuates mitophagy to exacerbate cardiac damage after ischemia. $J$ Mol Cell Cardiol 2012; 52: 175-184.

21. Merritt AJ, Potten CS, Kemp CJ, Hickman JA, Balmain A, Lane DP et al. The role of p53 in spontaneous and radiation-induced apoptosis in the gastrointestinal tract of normal and p53deficient mice. Cancer Res 1994; 54: 614-617.

22. Komarova EA, Kondratov RV, Wang K, Christov K, Golovkina TV, Goldblum JR et al. Dual effect of p53 on radiation sensitivity in vivo: p53 promotes hematopoietic injury, but protects from gastro-intestinal syndrome in mice. Oncogene 2004; 23: 3265-3271.

23. Hock AK, Lee P, Maddocks OD, Mason SM, Blyth K, Vousden KH. iRFP is a sensitive marker for cell number and tumor growth in high-throughput systems. Cell Cycle 2014; 13: 220-226.

24. el-Deiry WS, Tokino T, Velculescu VE, Levy DB, Parsons R, Trent JM et al. WAF1, a potential mediator of p53 tumor suppression. Cell 1993; 75: 817-825.

25. Osada M, Nagakawa Y, Park HL, Yamashita K, Wu G, Kim MS et al. p63-specific activation of the BPAG-1e promoter. J Invest Dermatol 2005; 125: 52-60.

26. Liu $G$, Chen $X$. The $C$-terminal sterile alpha motif and the extreme $C$ terminus regulate the transcriptional activity of the alpha isoform of p73. J Biol Chem 2005; 280: 20111-20119.

27. Zhu J, Jiang J, Zhou W, Chen X. The potential tumor suppressor p73 differentially regulates cellular p53 target genes. Cancer Res 1998; 58: 5061-5065.

28. Ishimoto O, Kawahara C, Enjo K, Obinata M, Nukiwa T, Ikawa S. Possible oncogenic potential of DeltaNp73: a newly identified isoform of human p73. Cancer Res 2002; 62: 636-641.

29. Liu G, Nozell S, Xiao H, Chen X. DeltaNp73beta is active in transactivation and growth suppression. Mol Cell Biol 2004; 24: 487-501.

30. Moll UM, Slade N. p63 and p73: roles in development and tumor formation. Mol Cancer Res 2004; 2: 371-386

31. Nozell S, Wu Y, McNaughton K, Liu G, Willis A, Paik JC et al. Characterization of p73 functional domains necessary for transactivation and growth suppression. Oncogene 2003; 22: $4333-4347$

32. Agami R, Blandino G, Oren M, Shaul Y. Interaction of c-Abl and p73alpha and their collaboration to induce apoptosis. Nature 1999; 399: 809-813. 
33. Gong JG, Costanzo A, Yang HQ, Melino G, Kaelin WG Jr., Levrero M et al. The tyrosine kinase c-Abl regulates $p 73$ in apoptotic response to cisplatin-induced DNA damage. Nature 1999; 399: 806-809.

34. Yuan ZM, Shioya H, Ishiko T, Sun X, Gu J, Huang YY et al. p73 is regulated by tyrosine kinase C-Abl in the apoptotic response to DNA damage. Nature 1999; 399: 814-817.

35. Sato T, Vries RG, Snippert HJ, van de Wetering M, Barker N, Stange DE et al. Single Lgr5 stem cells build crypt-villus structures in vitro without a mesenchymal niche. Nature 2009 459: 262-265.

36. Donehower LA, Harvey M, Slagle BL, McArthur MJ, Montgomery CA Jr., Butel JS et al. Mice deficient for p53 are developmentally normal but susceptible to spontaneous tumours. Nature 1992; 356: 215-221.

37. Tomasini R, Tsuchihara K, Wilhelm M, Fujitani M, Rufini A, Cheung CC et al. TAp73 knockout shows genomic instability with infertility and tumor suppressor functions. Genes Dev 2008 22: 2677-2691.

38. Ashton GH, Morton JP, Myant K, Phesse TJ, Ridgway RA, Marsh V et al. Focal adhesion kinase is required for intestinal regeneration and tumorigenesis downstream of Wnt/c-Myc signaling. Dev Cell 2010; 19: 259-269.
39. Sansom OJ, Reed KR, Hayes AJ, Ireland H, Brinkmann H, Newton IP et al. Loss of Apc in vivo immediately perturbs Wnt signaling, differentiation, and migration. Genes Dev 2004; 18: $1385-1390$

40. Vigneron AM, Ludwig RL, Vousden KH. Cytoplasmic ASPP1 inhibits apoptosis through the control of YAP. Genes Dev 2010; 24: 2430-2439.

(c) (i) Cell Death and Disease is an open-access journal published by Nature Publishing Group. This work is licensed under a Creative Commons Attribution 4.0 International License. The images or other third party material in this article are included in the article's Creative Commons license, unless indicated otherwise in the credit line; if the material is not included under the Creative Commons license, users will need to obtain permission from the license holder to reproduce the material. To view a copy of this license, visit http://creativecommons.org/licenses/by/4.0/

Supplementary Information accompanies this paper on Cell Death and Disease website (http://www.nature.com/cddis) 